\title{
Foraging Behaviour Patterns of Herring Gulls Elicited by Electrical Forebrain Stimulation
}

Herring gulls (Lavus argentatus) are coastal scavengers. Mostly they obtain food by visual exploration during flying or walking, and then simply approaching likely items. Occasionally though, they use more sophisticated foraging behavior such as robbing other birds of their prey by harassing them, plunge diving in the style of terns (Sterna $\mathrm{sp.}$ ), cracking shell-fish by dropping them from a height on to hard patches of beach, or 'paddling'. During this latter behavior herring gulls, and a number of other gull species which show an essentially identical deportment, step on the same spot alternately with their webbed feet while looking intently at the ground immediately in front of them. In the wild they perform this behaviour mostly whilst standing in shallow tidepools or on slushy mud, and from time to time they can be seen jabbing quickly to pick up some small object which they then appear to swallow. It has been argued that the trampling stirs small animals dwelling in the sand up to the surface which thus become visible to the gulls. Various sources of evidence indicate that this

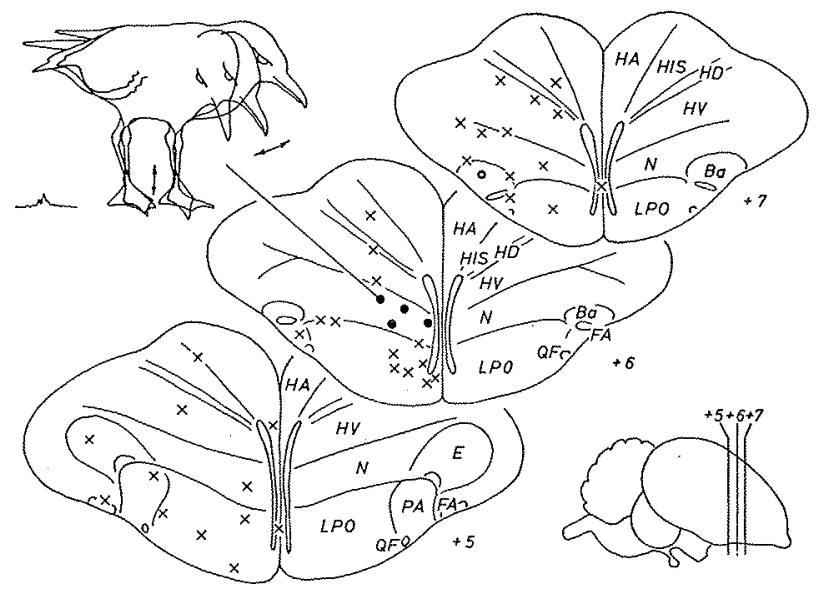

Location of electrode tips yielding 'paddling' (dots) and 'fish handling' (circle) behaviour in the herring gul. Crosses indicate sites eliciting other behaviour. Some 250 negative loci elsewhere in the brain have been omitted. For convenience all loci have been transferred to the left side. The insert illustrates the paddling elicited by one of the electrodes, drawn from an $8 \mathrm{~mm}$ film. Abbreviations: Ba, nucleus basalis; E, ektostriatum; FA, tractus frontonarchistriaticus; HS, hyperstriatum accesorium; HD, hyperstratum dorsale; HIS, hyperstriatum intercalatus superior; $H V$, hyperstriatum ventrale; LPO, lobus paraolfactorius; N, neostriatum; PA, paleostriatum augmentatum; QF; tractus quinto-frontalis.

1. F. Goexne, Die Sibermöwe (Ziemsen, Wittenberg 1956).

2 N. TrNBergen, Die Welt der Silbermöre (Musterschmidt, Göttingen 1958)

${ }^{3}$ P. A. Buckex $x$, Z. Tierpsychol. 23, 395 (1966).

4 Several shore and meadow feeding bird species other than gulls show behaviour patterns resembling paddling in feeding contexts, suggesting a polyphyletic origin of analogous behaviour ${ }^{3}$.

s While conditioning our captive gulls in an operant situation, Dr. G. THOMPSON noticed that when the apparatus falled to deliver a piece of meat the birds had learned to expect as reward for pecking a key, they often wonld begin to paddle on the'sawdust covered cement floor. I myself saw them repeatedly begin to paddle after loosing morsels of food in puddles of turbid water where they were washing them clean of sawdust. There was no doubt that this was a successful method of recovery. It is true though that flooded cage floors sometimes would induce a veritable frenzy of padding without the gulls showing any interest in possible food items. I can also interpretation is correct even though often, particularly in captivity, gulls will show paddling behaviour in functionally inadequate situations such as on solid cement floors, or when it can be inferred that they are not motivated by hunger ${ }^{1-5}$.

During an exploration of the forebrain of gulls with electrical stimulation ${ }^{6-10}$, I obtained, apart from other behaviour, precisely this paddling pattern. 4 electrodes with tips located in the anterior telecephalon yielded a sequence which the gulls began by looking down at the floor in front of them scanning it visually with small amplitude, jerky head movements, the head held somewhat forwards and downwards. The accompanying eye movements suggested that the gulls were successively fixating, both monocularly and binocularly, different points on the floor. At the same time they moved their feet in a slow, treading manner (about 2 to 3 steps per sec), typically without shifting from the site they were standing on (Figure).

While usually both components, the visual scanning and the stepping, began nearly simultaneously, sometimes one or the other was delayed or even absent on any given stimulation trial. 2 of the electrodes also elicited a mild interest in edible items in conjunction with the paddling: the birds would peck at, and often pick up, morsels of fish or meat within their reach even though they had paid no attention to them before stimulation. When tested hungry, this interest seemed to be increased but only once or twice did they actually swallow the food; for some reason the gulls were generally, whether stimulated or not, very reluctant to eat in the testing cage. If no edible items were available, the gulls were prone to direct tentative pecks at pebbles, bolts, a length of wire, a pencil and such like.

The threshold currents varied quite considerably from trial to trial $(40 \mu \mathrm{A}$ to $90 \mu \mathrm{A})$ but they were similar for all 4 electrodes and, in comparison with thresholds for other responses and electrodes, they were within a medium range. While some of the variability was doubtlessly due to adaptation to the stimulus current it was obvious that much of it was related to the fact that the paddling was easiliy inhibited by competing responses. Fear induced by incidental stimuli was a common disturbing factor. 2 of the electrodes also induced an ipsilateral turning tendency at currents similar to those eliciting paddling. Mostly the turning was simply superimposed on the paddling, but sometimes it was strong enough to interfere with it. At higher currents, above $100 \mu \mathrm{A}$, all electrodes gave strong ipsilateral turning behaviour, doubtlessly due to the unilateral stimulation of a bilateral structure, which suppressed any paddling the gulls might have shown.

confirm the finding of others ${ }^{1-3}$, that the paddling develops in herring gulls reared from the egg onwards in isolation from adult conspecifics on hard floors, that is even when the pattern is never followed by any conventional reward. Thus the behaviour is, loosely speaking, innate.

6 J. D. Delius, J. small Anim. Pract. 7, 605 (1066)

; J. D. Delrus, Biol. Med. Engng. 4, 393 (1966).

8 J. D. Delius, Nature, Lond. 274,1259 (1967).

9 J. D. Delius, Expl. Brain Res. 12,64 (1971)

10 Fifty handraised juvenile herring and lesser black backed gulls were implanted under anaesthesia ${ }^{6}$ with up to 8 chronic monopolar, insuiated $0.1 \mathrm{~mm}$ diameter stainless steel electrodes with $0.25 \mathrm{~mm}^{2}$ uninsulated conical tips ${ }^{7}$. After recovery, they were stimulated with repeated $30 \mathrm{sec}$ to 5 min trains of $50 \mathrm{~Hz}$ sine currents up to $200 \mu \mathrm{A}$ rms for several sessions including interspersed control trials, over 2 or more months in a $4 \mathrm{~m}^{3}$ cage. Electrode tip locations were ascertained histologically. 
Hence the reliability of the response being elicited on any given trial was not very high, ranging between $43 \%$ to $71 \%$ for the various electrodes. The behaviour, however, was never seen during control trials. The response latencies varied between 3 to $10 \mathrm{sec}$ from trial to trial but they were similar for all electrodes. The visual scanning component of the paddling was marginally more reliable than the paddling per se and probably had a slightly lower threshold and a shorter latency ${ }^{11}$. The response did not persist after stimulation for more than 2 to $4 \mathrm{sec}$ and within 10 to $15 \mathrm{sec}$ the birds had usually returned to pre-stimulation behaviour. Using repeated stimulation, I could not detect any systematic effect of foregoing trials on latency, reliability etc., apart from an irregular but recurring, short lasting $(5 \mathrm{~min})$ increase in threshold.

The 4 electrodes in question were found to be located in the anterior neostriatum at the same cross-section level as the posterior pole of the nucleus basalis. The area yielding this response appeared to be quite restricted. Electrodes with tips only millimeters away in neighbouring stuctures or in the neostriatum at more posterior or anterior levels gave rise to quite different behaviour syndromes (Figure).

The involvement of the avian telencephalon in the control of feeding behaviour has been recursively mentioned in the older literature, a common observation being that forebrainless birds are not able to feed for themselves ${ }^{12}$ A modern investigation confirms this ${ }^{13}$. Some older reports, however, also indicate that de-telencephalated birds can recover the ability to feed ${ }^{12}$, and a somewhat more recent study similarly supports this ${ }^{14,15}$.

Lately, the feeding behaviour deficit arising from telencephalic ablation has been related to the destruction of a neural system consisting of the quinto-frontal tract which originates in the main sensory nucleus of the trigeminal nerve and terminates in the nucleus basalis in the anteriot telecephalon ${ }^{16-18}$. This nucleus in turn projects to the dorsolateral archistriatum via the tractus fronto-archistriaticus ${ }^{17,19}$. Bilateral lesions affecting these structures lead to a more or less persistent aphagia ${ }^{20}$. Coagulations placed symetrically in various areas of the hypothalamus also induce aphagia ${ }^{21,22}$. Some of these lesions probably have this effect because they interrupt the quinto-frontal tract or the efferent descending pathway of the system, the occipito-mesencephalic tract originating in the dorsal archistriatum ${ }^{17}, 23,24$, as these two tracts course through the diencephalon.

A recurring report regarding this lesion-induced aphagia is that the birds continue to demonstrate an interest in food by pecking at it and are capable of swallowing it when it is placed at the back of their gape, but that they are unable to grasp and mandibulate it. Hence, it is relevant to mention here an electrode with the tip located in the core of the nucleus basalis of a herring gull. It reliably yielded ( $96 \%$ of the trials), with a threshold current of $40 \mu \mathrm{A}$ and a $5 \mathrm{sec}$ latency, a characteristic action of upward jerky head motions and snapping bill movements with which gulls normally handle fish, so that it comes to lie head first in their gape, ensuring a swallowing unimpeded by bristling fins and scales ${ }^{25}$. The elctrode, however, did not induce any interest in actual fish, or for that matter, in any food, and thus the behaviour was invariably shown in vacuo. 2 electrodes with tips located in the periphery of the nucleus basalis produced only incipient snapping movements.

Concurring with the finding of other authors ${ }^{26,27}$, on different species, I found that several electrodes with tips situated within other components of the above mentioned circuit in the gulls, also elicited 'oral' behaviour elements, such as pecking, mandibulation, bill snapping, bill shaking and vomiting. Some, however, dicl not and electrodes located in several other, as far as known unrelated, brain structures did, in fact, produce similar patterns ${ }^{28}$. Indeed, stimulation of apparently equally unrelated sites in the anterior hypothalamus have been reported to yield compulsive feeding in pigeons 28,30 and facilitation of feeding has been elicited from widely distributed points within the telencephalon of doves ${ }^{31}$. This data suggests a complex contribution of a variety of forebrain structures to the patterning of avian feeding behaviour ${ }^{32}$.

That the involvement of the anterior neostriatum, the area yielding paddling in our gulls, is an important and general one however, is supported by reports based on comparative studies that the development of the anterior neostriatum and the immediately overlying hyperstria-

11 The staring down which I have mentioned as a component of another behaviour syndrome elicited by brain stimulation in gulls ${ }^{8}$ is quite distinet from the looking down accompanying the paddling, in that it lacks the sidewards, scanning head movements of the latter.

12 J. Ter Cate, Ergebn. Biol. 73, 93 (1936).

13 B. Akerman, E. Fabricius, B. Larsson and L. Steen, Acta physiol. scand. 56,286 (1962).

14 R. Truver and G. Perers, Pfliigers Arch. ges. Physiol. 240, 503 (1938).

15 In mammals the involvement of the forebrain in feeding behaviour appears to be less pronounced, while the key role of the diencephalon of course is well documented (P. M. Mnever, Physiological Psychology (Holt, Rinhart and Winston, London 1970)). Oral behaviour can however be obtained upon forebrain stimulation, e.s. swallowing from the frontal cortex (A. CAR, J. Physiol., Paris 62, 361 $(1970))$.

16 A. WALlendBerg, Neurol. Zentbl. 22, 98 (1903).

17 C. U. A. Kappers, G. C. Huber and E. C. Crosby, The Comparative Anatomy of the Nervons System of Vertebrates (Hafner, New York 1960).

18 It is difficult, at best, to equate any of the avian forebrain structures mentioned with the more familiar mammalian ones. The quinto-frontal tract in particular seems to be an avian peculiarity (W. J. H. Nauta and H. J. Karten, in The Neurosciences, Second Study Program, (Ed. O. F. SchmrTr; Rockefeller University Press, New York 1970).

19 T. Kondo, J. Okayama med. Soc. 45, 133 (1933).

${ }^{20}$ H. P. Zeigrer, H. L. Green and H. K. Karten, Psychon. Sci $15,156(1969)$.

21. S. E. Feldman, S. Larsson, M. K. Dramck and S. Lepovskx, Am. J. Physiol. 191, 259 (1957).

22 P. Wrageit, Psychon. Sci. 73,133 (1968)

23 T. Kondo, J. Okayama med. Soc. 45, 124 (1933).

24 Another efferent pathway which may need to be considered here is the tractus fronto-quintalis et bubaris (A. WAlleniser, Arch. Psychiat. NervKrankh. 94, 246 (1931)).

25 G. L. Hunt and W. J. Smith, Ibis 106, 461. (1964).

26 R. E. Pullips, J. comp. Neurol. 122, 139 (1964).

27 P. T. S. Putronen, Ann. Acad. Sci. Fenn. A730, 1 (1967)

${ }^{38}$ It should be mentioned though that 2 electrodes with tips located within the quinto-frontal tract, as it courses through the ventral telencephaton of the gulls, elicited reliable and definite pecking behaviour.

29 B. Akerman, B. Andersson, E. Fabrictus and L. Svensson, Acta physiol scand, 50, 328 (1960).

30 Hyperphagia has been induced in birds by lesions in the preoptio area (W. J. Kuenzel and C. W. Hedus, Condor 72, 66 (1970)).

31 D. Harwood and D. Vowles, J. comp. physiol. Psychol. 62, 388 (1966).

32 That a complex network is responsible for the control of feeding in birds is also suggested by system analytic studies (D. J, MCFARLAND, J. psychoson. Res. 14, 229 (1970)).

${ }^{33}$ W. Strwatin, Verh. naturf. Ges. Basel 73, 300 (1962).

34 One is tempted to predict, disregarding note 4 , that upon stimulat. ing the corresponding brain area in gallinaceous birds one would obtain the well known ground scratching they use for finding food, but this is precisely a feeding behaviour that forebrainless domestic chicks apparently retain (E. G. Martin and W. H. Rrch, Am. J. Physiol. 46, 396 (1918)). 
tum ventrale of various avian species correlates positively with the complexity of their feeding habits ${ }^{33,34}$. In view of behavioural evidence indicating that information from the feet and the eyes is important in releasing and coordinating the paddling behaviour ${ }^{1-3,5}$, I surmise that the neostrial area in question links the forementioned circuit, specifically the neighbouring nucleus basalis, with both a cutaneous ${ }^{35}$ and a visual sensory projection ${ }^{36}$ that exist within the overlying hyperstriatum. That the hyperstriatum projects to, among other structures, the neostriatum. has actually been shown anatomically ${ }^{37}$.

Zusammentassung. Zwei artspezifische Verhaltensabläufe, die Silbermöwen (Larus argentatus) bei der Futtersuche und Futteraufnahme zeigen, wurden durch elektrische Reizung begrenzter Bezirke des rostralen Vorder- hirns experimentell hervorgerufen. Diese Befunde stützen vergleichend-anatomische Schlussfolgerungen über die funktionelle Rolle des rostralen Vorderhirns bei Vögeln.

JUAN D. DELTUS ${ }^{38}$

Department of Psychology, University of Durham, South Road, Durham (England), 3 June 1971.

${ }_{35} \mathrm{~J}$. D. Deluus and K. Bennetro, Brain Res, in press (1971).

36 A. M. Revin, Brain Res. 15, 246 (1969).

37 N. J. Adamo, J. comp. Neurol. 137, 337 (1967),

38 The work was supported by grants from the United States Air Force, the Science Research Council and the Royal Society to Professor N. TrNBERGE and myself. It was partially carried out at the Department of Zoology, Oxford, The assistance of Dr. G. Trompson and Mr. A. JACKson is gratefully acknowledged. 